\title{
The "Performatic Mantras" of Copyright
}

\section{Victor Gameiro Drummond}

Post. Doc. - Universidade de Lisboa; Phd - Universidade Estácio de Sá - Rio de Janeiro; LLM/Master - Universidade de Lisboa; Professor of Law at PPGD Faculdade Guanambi. Visiting researcher at Universidade Complutense de Madrid e Universidade de Lisboa.

\begin{abstract}
The realm of copyright is experiencing a serious crisis. This has partly resulted from opposition between proponents of conservative and libertarianist schools of thought. In the face of such polarisation and radical opposition, definitions of copyright do not give space for philosophical and hermeneutical conceptualisations that may improve understandings of its rationale and philosophical foundations. Thus, both schools make use of "performatic mantras", which intensify conflicting relationships and ideological positions. This article shows that "performatic mantras" cannot be used in a pernicious manner and that the recovery of copyright worth involves a review of schools that examine it.
\end{abstract}

Keywords: Copyright, hermeneutics, philosophy, philosophical justifications, theoretical foundations of copyright.

\section{INTRODUCTION: JUSTICE, LANGUAGE AND COPYRIGHT}

Some might say that Law is synonymous with Justice. It is known, however, that this is not true. Law may entail a search for Justice. This search, however, involves respecting the foundations of Justice in Law.

Law is also a specific language, and thus it may be said that Law can be fundamentally defined as a form of language. ${ }^{1}$

By means of language, the basis of Justice can also be extracted from Law. Language (of and in Law) and the sense of Justice thus form the building blocks of Law.

In this same vein, legal hermeneutics, acting upon language, should ensure that the foundations of Justice extracted from Law are divested of ideologies so that truth of the Law can emerge.

Copyright, like any other category of Law, occurs, therefore, in language. In emerging from ideologies, copyright is also deficient in its use of language, hindering its development and examination.

Certainly, difficulties in defining copyright (and other factors) stem from ideological conceptions that make use of language by means of convincing through rhetorical exercises.

Hence, as in any other area of knowledge, the thinker, consumed by an ideological fog, cannot understand other perspectives.

Arguments that are not receptive to opposition do not reflect truth or effective truth, but instead constitute ideology. The only "ideology" that considers the other (if understood as a political philosophy or mode of communication between speakers) is democracy. Debates concerned with copyright must be legitimately democratic, and thus all participatory bodies must see one another. This does not occur at present.

This absence of a frontal, non-ideological debate regarding Law has serious consequences for the construction of Law and for definitions of justice in the so-called authorial sector (i.e., the cultural and entertainment sectors). I thus view copyright as a breeding ground for the proliferation of what I have been calling "performatic mantras".

\footnotetext{
${ }^{1}$ Kaufmann states that "[...] law is produced by language [...]". A Kaufmann, Filosofia do Direito [Philosophy of Law] (CalousteGulbenkian Foundation, Lisbon 2004), 165.
} 
That is, copyright, through its apparent and effective villainy, apathy vis-a-vis philosophical discussions, anaemia of arguments of philosophical and hermeneutical ink exhibited through copyright knowledge ultimately allows for a consequent ideologism of a difficult recantation of exaggeration, even within academia. This is reflected in uses of "performatic mantras" in copyright environments that do not respect academic discussions and that are often clothed in academicism yet supported by (not always legitimate) interests.

To lift the veil from artificial applications of arguments on copyright would allow for debate. To expose the mistakes of artificiality based on ideologised ideas is fundamental to this very debate.

It is my understanding that a significant portion of conflicts inherent to copyright and copyright crisis result from the use of so-called "performatic mantras", which are duly described.

\section{LibERTARIANISTS AND CONSERVATIVES: EXPENDABLE ANTAgONISTIC OBJECTIONS}

Copyright is unique in its allocation of villainy and antagonistic positions. Since its first formal appearance during the mid-18th century with the emergence of pro-author political positions, there were strong objections to the consolidation and solidification of copyright. At the time, private property served as one of the (ideo) logical foundations of copyright, and it remains so to the present day.

These antagonisms were strengthened along the years, specially over the oppositions to simple foreign economic interests that were often disguised as true and legitimate rights.

Successively, oppositions have intensified up until the situation nowadays: opponents to the literary or intellectual property and defenders of private property; authors and editors; music companies and artists; collective management entities (associations) and users; owners and consumers; owners and Internet access providers and new technologies.

Today, among various effective and apparent conflicts at play, there is a dichotomy between activities that include more liberal postures and conservative tendencies. Both are often justifiable.

This led me to identify two main groups of (often falsely) justified philosophical postures and tendencies. Fundamentally, I define this dichotomy - in terms of performances and ideas generally named as schools of thought - as conservatives on one side and libertarianist on the other.

It should be highlighted that I make use of the expressions "libertarianist" and "conservative" to categorise interpretive tendencies of contemporary copyright. It is important to note that the terms "libertarianist" or "conservative" do not imply any judgement of qualitative value, but simply a synthetic opposition (and thus consciously risky) identified in articles, historical discussions, philosophical assessments and thoughts that I examine. Generally speaking, any attitude can be considered "conservative" or "libertarianist". This does not imply that such classification should be used to disqualify whoever acted in a way that might be identified as either behavioural pattern. These classifications are operational and not essentially qualifying in essence. If they are meant to have a qualifying weight it will be expressly identified. I understand that some positions that I present can be considered "conservative" and partially "libertarianist" without this reflecting a conceptual, philosophical or legal error. I reiterate that attitudes are associated with one or the other but it should be considered that the criteria of allocation and nomenclature are also based on an interpretation that I propose in this text, implying on a relativisation of such concepts to the way I observe attitudes of the examined copyright authors.

Firstly I must indicate that the expression "libertarianist" is deliberately reductionist to synthetically state that some thinkers who have worked in the area of copyright and intellectual property tend to liberate or make some protective copyright content flexible through attitudes that sometime offer revitalisation, and other times excessive fragmentation or a reconceptualisation of copyright and its content at various times. This markedly reductionist expression was employed to avoid the use of expression "liberal" (given the clear semantic conflict that would arise with concepts of liberal movements of the 18th century). I also choose not use the expression "libertarian", as this may imply a use of discriminatory content mingled with certain revolutionary ideals that I do not intend to refer to. The expression "libertarian" has also been used in other contexts. The term "libertarian" is used in Portuguese and Spanish texts for example, to refer to subjects who subscribe to notions of libertarianism, signifying the translation of contemporary understandings of effectively liberal (or 
markedly liberal) political philosophies of the United States, as seen in many sources such as Michael J. Sandel's work Justice. ${ }^{2}$ In the original English-language text, Sandel makes use of the expressions libertarianism and libertarian to denote the philosophical libertarian vein and its suporters, respectively. ${ }^{3}$ My use of the expression "libertarianist" does not therefore refer to contemporary, political and moral philosophical ideas relating to the expressions listed. Rather, as has already been shown, I use the "libertarianist" expression to oppose the definition of the term "conservative".

Conservatives, thus, are those thinkers who do not show any (or perhaps just a little) tendency towards flexibilitzation or towards a deviation from the application of the systematic contents of copyright in either of its main systems, be it droitd'auteur or copyright. Hence, it is an evident and consequent reductionism justified by the opposition to the term that it seeks to oppose.

As it will be demonstrated, I understand that the ideologized practice and the promotion of opposition does not significantly contribute to a comprehensive philosophical understanding of copyright. Much to the contrary, the radical opposition to the stated thought tends to challenge the construction of the philosophy of copyright.

I understand that categorization is needed to illustrate how the tendencies of copyright's schools of thoughts are oppositional.

\section{3. "Performatic Mantras" and Their Contribution to the Philosophical DEFICIT OF COPYRIGHT LAW ${ }^{4}$}

Conservative and libertarianist schools, tendencies, and postures make use of "performatic mantras" to consolidate highly ideologised ideas.

"Performatic mantras" are expressions emptied of their effective content that are used to seek a rhetorical conviction of copyrightist ideas. Thus, the use of expressions such as copyright is contradictory and offensive to the freedom of expression; culture is free; and copyright protects creators; disables copyright law application and its illegitimate use.

This illegitimate use can be done by large corporations that seek to build large databases or to charge for the access to given content, representatives of rights holders, copyright holders and various associations, consumer associations, entities of collective management and various other agents active in the copyright scene that make use of "performatic mantras" to promote ideas ideologically contrary to others copyright's schools of thought (i.e., - as per my suggestion - naturally conflicting conservative and libertarianist schools).

Nonetheless, "performatic mantras" are expressions used for symbolic and often illegitimate reasons due to exaggerated (and often conflicting) definitions and the philosophical deficit of copyright. Alternatively, when they are not necessarily used in the form of sentences, but in the form of ideas instead, repeated ad nauseam, they inspire a false conviction of societal values that strengthens the

\footnotetext{
${ }^{2}$ Michael J. Sandel is a professor of philosophy at Harvard who teaches the university's most sought-after course entitled Justice. He published, among other works, the book Justice - What's the Right Thing to Do, which includes the main principles of the above-mentioned course and which was translated into various languages.

${ }^{3}$ The author states that, “(...) Libertarians favour unfettered markets and oppose government regulation, not in the name of economic efficiency, but in the name of human freedom". He also states that there are three types of rejected policies that are applied by contemporary States in modern times: paternalism (as political postures or legislative policies), laws on moral issues, and laws on the redistribution of income and property. M Sandel, Justice - What's the Right Thing to Do (Farrar, Straus and Giroux, New York 2009), 59.

${ }^{4}$ Copyright's philosophical deficit has resulted from factual/temporal circumstances rooted in the misinterpretation of time immemorial and from definitions of copyright that consider subject-creator conditions while disregarding the essence of creative processes in historical, legislative, and philosophical analyses. The philosophical deficit stems from the primordial fact that copyright, since its conceptualization as a legal category, was always acclimated, interpreted and developed without an analysis of pure philosophy and always bounded by concepts of economy, politics, and of the representation of interests that were often not even directly related to the subject-creator. Uses of expressions that do not match the philosophically correct (or appropriate, to say the least) meaning, such as copyright and artistic-literary property, and an acceptance of the validity of the "cry of Chapelier", which I consider the first "performatic mantra", illustrate the nature of the philosophical deficit.
} 
theoretical premise of copyrightists, preventing effective reflection - especially from a philosophical viewpoint. "Performatic mantras" can be conveyed through written texts; conference presentations, lectures and seminars; legislative texts; written or verbal advertising materials).

The biggest danger of using "performatic mantras" is emptying the authenticity or correctness of content through the use of ideas outside context, exaggeratedly, either in ideological form or using non sequitur arguments.

Its use by companies that have a direct interest on information and cultural goods having low cost or no licensing cost at all, is an example of the use of mantric expressions seeking to symbolically empt copyright law by affirming that the Internet is a free territory or that copyright offends the freedom of access to culture.

While the Internet ought to be a free territory, the existence of copyright (on its own) does not prevent Internet freedom. Other obstacles exist, and not all works protected by copyright hinder the freedom of access. Moreover, as copyright law can be by its very nature relativised, to state that it constitutes an obstacle, from a hermeneutics perspective, renders its relativisation impossible, which is highly paradoxical.

On the other hand, it is also verified the use of "performatic mantras" when expressions are used to indicate that all attitude - political and that seek to defend copyright law-are a consequence of the intention to protect author interests. Such expressions are often employed by large corporations and management entities that seek to confuse the figure of the subject-creator ${ }^{5}$ with the owner of the economic rights of the author. Such a "performatic mantra" transforms the principle, despite its essentially and theoretically valid content, into a fallacious argument as the one using the expression is not the subject-creator or when definitions of the subject-creator are changed without respecting issues of equality.

More libertarianist tendencies to relativise copyright oppose this idea through the adoption of new property conceptualisations by some authors such as Souza and Mizukami, ${ }^{6}$ among others. Souza, for example, understands that solutions to the contemporary copyright crisis are premised "[...] in the analysis of the horizontal extension of asset protection based on collective rights equally and necessarily incurred in the verification of the amplitude of such protection".

\footnotetext{
${ }^{5}$ The "subject-creator" constitutes the central figure of what I call the contemporary philosophy of copyright. I realize that the best means of assigning a name to the autonomous subject of philosophy and to the author, in basic conceptualizations (which are examined) of Law, would involve a concomitant use of the expressions "subject" and "creator". On the other hand, terminologies inherent of the term "author" raise many questions surrounding its meaning and regarding how the author under review is originally a nineteenth-century author (with this perception being adopted since Descartes and later by Kant) as well as an author of individual creative conception. I thus realize that it was prudent to use the expression "creator" together with "subject". Moreover, the term "author", which is often confused with copyright (at times ideologically and in deliberately confusing ways), can promote an understanding of an "author" as a "rights-owner", potentially confuse this subject with holders that are not physical entities (to use a typical legal expression). The expression "subject-creator" is occasionally used as a synonym for an author considered at the time (when the modern, post-Cartesian author, is analysed, for example) and when the nineteenth-century author, who already appears in Kant and in the French Revolution, is considered. Likewise, allow me to use the expression "author" when, in the sense of this article, it would make sense to discuss how this has been used historically (and thus with countless references made by other thinkers). In addition, I use the terms "author" or "subject-creator" to give fluency to the text, as "subjectcreators" and "authors" are not historically distinguished in conceptualizations of this concept, though I understand that contributions that generated meanings of the "subject-creator" are found through an understanding of post-linguistic turn authorship. The idiomatic construction that I refer to, however, responds to a notion of the "subject-creator" following paradigmatic disruptions of its modern appearance (I focus on Descartes) at the advent of the philosophy of consciousness (that I see in Kant) and in the linguistic turn (given the obvious prominence of Heidegger and Gadamer). On the other hand, it is worth noting that I use the expressions "author" and "authors" to refer to thinkers who address the theme explored in this article, be they philosophers, attorneys, or authoralists.

${ }^{6}$ P Mizukami, 'Função Social da PropriedadeIntelectual: Compartilhamento de Arquivos e DireitosAutorais da CF/88 [The Social Function of Intellectual Property: File Sharing and Copyright of CF/88]', [2007] USP <http://www.sapientia.pucsp.br/tde_busca/arquivo.php?codArquivo=5101> accessed on 15 December 2013.

${ }^{7}$ A Souza, A Função Social dos DireitosAutorais: Um Interpretação Civil-Constitucional dos Limites da ProteçãoJurídica. Brasil: 1998-2005 [The Social Function of Copyright: A Civil-Constitutional Interpretation
} 


\section{Extraction of the Philosophical Valuation of Copyright: The Need to COUNTERACT VILLAINY}

The arguments of each of the mentioned schools (or tendency) (conservative or libertarianist) should be understood through the philosophical or fundamentally philosophical bias so that the essence of copyright can be extracted in its complex meaning, properly averting, from the outset, its (pre)conceptions. ${ }^{8}$ This is the only way for the development of a real, appropriate and fair hermeneutic space for copyright.

However, this is not what usually happens and therefore, ideology takes the space of the more neutral philosophical reflexions, to say the least.

On the other hand, it is also relevant to indicate that copyright is obviously not exclusively relevant to economics and thus, economic values inherent to cultural environments are relevant both form this perspective as well as from a philosophical one. I make note of this because some arguments of each school (libertarianist or conservative) are based on economic (valuable) principles but they are not my way to begin resolving the conflicts. ${ }^{9}$

Nonetheless, the use of philosophical arguments in service of economic interests constitutes a simple and false philosophical veneer that does not sustain itself, as such arguments, as proposed, do not sufficiently justify certain stances. In this sense, an Internet content and access provider that insists on the idea that copyright, has as its "natural predator" the freedom of access or creation, highlights the use of economic bias falsely philosophical, contributing for the increase of a deficit to copyright.

In contrast, through my observations, I have been finding that my proposed philosophy of copyright presents more complex solutions, precisely through the understanding of subject-creator positions, and of all of the consequent conclusions that have historically (and ideologically) been drawn. I understand, effectively, that it is necessary to understand copyright based on the hermeneutics of artistic creation, which consequently gives, at the bare minimum, an answer or (if preferred) a more adequate response to the comprehension of what has been construed as copyright, particularly on inadequate philosophical foundations. It may sound pretentious to imagine that all academic, doctrinal and pragmatic solutions to issues of copyright must be supported by philosophy and hermeneutics. Conversely, it is not pretentious to argue that it is only with an effective use of philosophical lens that it is possible to really see the core of copyright discussions, which through a hermeneutical perspective, could reach more density on the contributions to the understanding of copyright, including with regards to pragmatic solutions (which are typically polarised).

Given this context, it is my perception that the conflicts between conservatives and libertarianists arise, taking account of displaced fundamentals. "Performatic mantras"exacerbate these dislocations, consolidating the contradicting pressure inherent to the duality (between conservative and libertarianist positions) and further complicating copyright analyses.

The most classical of "performatic mantras" employed in latosensu analyses (helping its interpreters make use of its content through ideological objectives) is the historical and foundational declaration of Le Chapelier, whereby a French politician boasted in 1791 that the artistic-literary property constituted the "most sacred, most legitimate, most personal property of all properties". ${ }^{0,11}$

of the Limits of Legal Protection. Brazil: 1998-2015] (Law School of Campos, Campos dos Goytacases 2005), 265.

${ }^{8}$ Often dense and strictly repeated in the form of ideological loops, disabling opportunities for interruption.

${ }^{9}$ I realize that many authors present a meaningful and relevant account of the economic value of copyright, whose theses are strongly based on economic elements such as those of JoostSmiers and William Patry, who can be viewed as thinkers who "economicalised" (understandings of) copyright. See W Patry, Moral Panics and the Copyright Wars (Oxford University Press, New York 2009), 61 onward. Smiers, in addition to authoring various texts, co-authored a work with Van Schijndel that merits attention. See J Smiers and M Van Schijndel, 'Imaginem um MundosemDireitos de AutornemMonopólios - Um Ensaio [Imagine a World without Copyright or Monopolies - An Essay]', [2009] Institute of Network Cultures <http://livrosdoexilado.org/imaginem-ummundo-sem-direitos-de-autor-nem-monopolios-joost-smiers-e-marieke-van-schijndel-formato-pdf/ $>$ accessed on 15 February 2013 .

${ }^{10}$ For the original text, see L Bently and M Kretschmer (eds), Le Chapelier's Report, Paris [1791], Primary Sources on Copyright (1450-1900) <http://copy.law.cam.ac.uk/cam/ tools/request/showRepresentation.php?id= representation_f_1791\&pagenumber=1_15\&imagesize=small\#TranslationDisplay >accessed 10 June 2014;"“The 
I should state from the outset, however, that "performatic mantras" are not necessarily created by authors to support their own ideologised thesis. On this particular issue, I should highlight that great disseminators of "performatic mantras" are often not their authors, but those who use them to shift the focus of discussions or to institute judgements of value or of excessive worthlessness, thereby interpreting their content incorrectly. Nonetheless, it is possible to cite authors that do not necessarily had the intention to use their ideas as "performatic mantras", but which had their ideas developed by third parties through (dis)tempered judgements of value and worthlessness. It is not my place to describe such circumstances; rather, it is down to the reader to meditate on judgements and analyses when contemplating the so-called "performatic mantras".

Thus, the following phrases that I have heard ad nauseam configure "performatic mantras": (1) copyright violates freedom of expression; (2) copyright prevents access to culture; (3) culture is free; (4) the Internet is a free territory; (5) intellectual property is the most sacred of all properties; (6) collective management associations defend authors' interests; etc.

These are examples of "performatic mantras" that have highly symbolic value. They must be therefore, emptied of their ideologies and examined objectively so that it becomes possible to remove all hermeneutic linings allowing their true content and meaning to be identified.

Unappropriated uses of these mantras have been devaluing their real worth. Even if one extracts truth from, for example, the expression the Internet is a free territory (and there is much truth in it), its intemperate use (diverted from its true and proper position) and ideologisation lead to these mantric and ideological deviation (since the misuse weakens its meaning) as well as to the total semantic emptying as it becomes devoid of meaning.

For the protection of the legitimacy of the dialectical process, it is essential to maintain the value of the ideas, which is achieved respecting the language used to represent such ideas. If the language that represents the ideas is no longer meaningful, the effective content of such ideas dissolves. In other words, part of the idea is on the idea itself and the other part is on the significance conferred to them through language.

The repeated use of the expressions mentioned above, for instance, will result in an irreversible loss of meaning, impeding efficient reasoning and diminishing the opportunities for the best legal meaning to be extracted from the dialectic syntheses of copyright conflicts.

To a certain extent it has already happened to mantras (5) and (6) identified above, which are those prophesied by more conservative copyright authors, which ended up being denounced in an illegitimate defence of interests due to such semantic emptying.

Ramos, for example, reiterates the ideas presented by Le Chapelier:

...even if it is easily understood that the author copyright over his or her own creations represents the most legitimate form of property - perhaps the only form-this principle was already trampled by the first waves of cultural industry. ${ }^{12}$

Thus, in addition to making use of the referred mantra, the author helps to strengthen copyright's philosophical deficit. It should be clarified, however, that I do not argue that Ramos is wrong on seeking copyright protection. What I effectively note is the ideologised use of an expression under the form of a "performatic mantra" to support either libertarianist or conservative tendencies, as in this particular case.

most sacred, the most legitimate, the most unassailable, and if I can even say, the most personal of all properties is work emerging from the writer's thoughts: a property differing completely from other properties". Translated from: La plus sacrée, la plus légitime, la plus inattaquable, et, si je puisparlerainsi, la plus personnelle de toutes les propriétésestl'ouvrage fruit de la pensée d'un écrivain; c'estunepropriété d'un genre tout différent des autrespropriétés.

${ }^{11}$ In some ways, the title of the Statute of Anne, which previously (1710) included performatic-mantric content by citing laws that would benefit the majority of society by encouraging learning: (...) for the Encouragement of Learning, by Vesting the Copies of Printed Books to the Authors or Purchasers of such Copies (...).

${ }^{12}$ J Ramos, 'O Artista e osDireitos da Criação: Um Apartheid Autoral? [The Artist and Creation Rights: An Authorial Apartheid?]' inDoutrina - SériesobreDireitoAutoral [Doctrine - Series on Copyright] (Ministry of Culture, Brasília 1989), 12. 
Another author who makes use of the same mantra is Fernando Brant, a renowned composer of popular songs such as "Travessia" and a partner of the renowned Brazilian composer Milton Nascimento, among others. In the copyright scenario, Brant is seen as part of the group of directors of a Brazilian collective management music association called the Brazilian Union of Composers (UniãoBrasileira de Compositores - UBC), which manages the rights collection system of the Central Bureau for Collection and Distribution (Escritório Central de Arrecadação e Distribuição - ECAD). Brant assumes a radically conservative position, positioning himself against the Creative Commons licensing system and acting as a disseminator of the same "performatic mantra": "This is a concept that I should be clear: copyright is a property right. An original work, created by someone, belongs to its creator and is protected morally and materially" (emphasis added). ${ }^{13}$

When "performatic mantras" are employed to support heavily ideologised ideas, not only occurs the emptying of the mantras' content, but also a devaluation of their very tendencies. This has already occurred in more conservative schools, and is beginning to dawn as a result of the mistaken ideologisations promoted by libertarianists, implying in the fact that the subject-creator is the most heavily affected.

In this scenario therefore, it is thus crucial to rescue the position of the subject-creator, who is excessively weakened, as noted by Ascensão:

...the author is more of a victim than a beneficiary of the system. This is necessary, as the author must resort to this, and the author is the very justification of its existence-but the author has lost leading role. Managers of the system, be they authors themselves or not, are at the foreground. ${ }^{14}$

As an obvious loss, is the fact that true subject-creators and recipients of the creative process may be those most (if not the only ones) affected by this process of devaluation and consequent semantic emptying. In the case of pronounced mantric performance promoted by collective management associations, civil society upholds a biased view that, combined with offensive charges over the use of protected works, has inspired a generalised malaise among important copyright agents who need urgently to regain their credibility in civil society.

As for the more libertarianists contours, it would be urgently recommended that it utilised a more selective criteria on the use of the referred mantras, refraining from actually using the ideas as mantras but instead in a conceptually justified manner. This would avoid the risk of emptying them from their semantic, which can lead at a later stage, to the increasing on the difficulty of regaining the ideas credibility due to the distortions that could be applied to them.

There has already been happening a semantic emptying of various ideas, as in the case of mantra (2), for example, which states that copyright impedes access to culture. The overvaluation, vulgarisation, or even the mistaken use of ideas under the form of "performatic mantras" deflates the ideas'contents rendering them ineffective.

It is necessary to demonstrate objectivity for scientific findings to be uncovered, but first of all, it is important to determine whether the objective of the analysis is to defend particular interests or if it is to find (any) truth. If interests are being defended, the fight is misguided. My intention is to propose a way to the truth regardless of the conceptual or occasional affiliations of the presented ideas.

It is not problematic to subscribe to either libertarianist or conservative stances in different moments. I present my ideas comfortably from an academic perspective without the concern of being affiliated to one tendency or the other but already anticipating offensive criticism for a kind of "academic

\footnotetext{
${ }^{13}$ F Brant, 'Creative Commons é RenúnciaIrrevogável do Direito do Autor [Creative Commons is Irrevocable Waiver of Copyright]', (Lecture given at the 2006Festival de Cinema do Rio [Rio Film Festival], extracted from the newspaper publication Hora do Povo, 6 December 2006) <http://www.umes.org.br/index.php/nossasbandeiras/34-movimento-estudantil/nossas-bandeiras/em-defesa-da-cultura-popular-brasileira/161-brantcreative-commons > accessed on 22 December 2013.

${ }^{14}$ J Ascensão, 'A Supervisão da GestãoColetivanaReforma da LDA [The Supervision of Collective Management in the Reform of the Copyright Law]' in M Wachowicz (ed), PorqueMudar a lei de DireitoAutoral - Estudos e Pareceres [Why Change Copyright Law - Studies and Opinions]

(FundaçãoBoiteaux/EditoraFunjab, Florianópolis 2011), 155.
} 
schizophrenia" of which I can be accused of in the future - simply for identifying strong value arguments in each reading (regardless of its possible libertarianist or conservative affiliation) and for exhibiting a critical appreciation of copyright, which must be rescued from bias. Sincerity in this case, means philosophical honesty and application of contemporary hermeneutics.

\section{A Linguistic Turn Applied to Copyright}

"Performatic mantras" are maintained through their repeated use, resulting in an artificial consideration of true aspects of the conservative and libertarianist schools.

The use of "performatic mantras" as a conflict instrument, an ideology, or even an oppositional conflict poses another question of relevance to copyright that have still not been addressed by copyrightists: the application and comprehension of philosophies of language as a modification of the scientific view imposes the necessity of comprehending "performatic mantras" as an affront to the view that the philosophy of consciousness has been overcome (to include important elements of this philosophy).

In other words, to boast that "intellectual property is the most sacred of the properties" is an oversight from the Law standpoint and a confirmation of the lack of comprehension of the fact that language is not a simple channel between subjects and objects. The philosophy of consciousness supported the "performatic mantra" of Le Chapelier, but this makes sense as language has invaded philosophy through the linguistic turn.

It is similarly worth noting that phrase the freedom of access to culture is violated by copyright also excludes the philosophy of language from the history of philosophy. Attributions of "performatic mantras" are not permitted in the contemporary world, as they are permeated by symbolic meanings that must be extracted to comprehend what needs to be comprehended, and which is copyright's ever pursuit: what is the subject and why it deserves protection.

The extraction of purely symbolic value to reach the nucleus so involved in different layers of meaning stems, initially, from the understanding that the linguistic turn must also be verified by copyright theorists.

Copyright is still based in legal discussions of various rights and is therefore, less concerned with the philosophical justifications of copyright.

To identify philosophical justification(s) of copyright, it must be understood that the philosophy of consciousness no longer responds to copyright longings, as in the case of Law in general.

It is thus necessary to understand how an interpretive act is observed in the universe of Law. Thereunto, it is important to recognise that an insistent interpretation is still promoted based on a mistaken separation (in the contemporary world) of subtilitatae of classical hermeneutics, supporting the conclusion that part of the legal community does not understand a basic facet of Gadamerian philosophical hermeneutics: "interpretation is not a posterior and opportunistically complementary to understanding as understanding is always interpreting, and, as a result, interpretation is the explicit form of understanding" (emphasis added). ${ }^{15}$

Gadamer continues to indicate that, "our considerations force us to admit that in the processes of understanding, there is always something like an application to the text to be understood based on the interpreter's current circumstances". ${ }^{16}$ Gadamer rightly understands that this finding deviates its philosophical hermeneutics from romantic or classical hermeneutics, as the German philosopher understands that, "application is a moment of the hermeneutical process that is as essential and integral as understanding and interpretation". ${ }^{17}$

Now, it is important to understand that the creative act promoted by the subject-creator is, ultimately, an act of interpretation of the world, and through such act, in its conditions and through the process that transformed it into something creative, the existence of copyright is justified. Hence, the primordial philosophical justification of copyright is applicable to the subject-creator, thus excluding

\footnotetext{
${ }^{15}$ H Gadamer, Verdade e Método - TraçosFundamentais de umaHermenêuticaFilosófica [Truth and MethodFoundations of a Philosophical Hermeneutics] ( $3^{\text {rd }}$ edn Vozes, Petrópolis 2008), 459.

${ }^{16}$ Ibid. 460.

${ }^{17}$ Ibid.
} 
other important agents of copyright in this process of philosophical receptivity such as rights holders related to phonograms or broadcast firms.

Thus, in summary, if the linguistic turn proved that the fundamental subject-creator must be observed from the perspective of the philosophy of copyright, the reach of a fundamental subject is part of this process, and the use of "performatic mantras" inhibits access to the fundamental core of the subjectcreator.

\section{Conclusion}

Currently, to claim that intellectual property is sacred is the same as to render the position of the subject-creator as artificial, ultimately allowing any company to occupy the space of a subject-creator that does not belong to it and attributing copyright to large corporations that, in truth, exclusively seek profit growth. Therefore, copyright should not be attributed to rights-holding company of this nature and also property (definided and categorised as "sacred"), could not bear such nomenclature, positioning, or characteristics. However, this still occurs regardless. On the other hand, the contemporary sanctification of intellectual property (in this sense, I refer especially to the worlds of art, culture, and science that fall under the realm of copyright) imposes a confusion between the concepts of copyright holders, related rights, and subject-creator rights.

In contrast, users, who play a meaningful role in revenue acquisition, boast that access and usage should be free for the purposes of freedom, when in truth, this philosophical veneer is employed to increase profits. Users of creations have started to call themselves content providers, forgetting that a significant part of the so-called content is protected by copyright.

Hence, for both the defenders of rights holders as well as those who act in the name of users, "names of rights", faculties and applicable circumstances are assigned according to historicities that no longer apply, but which are maintained overtime using an artificial and myopic historicity. The artificiality of the phrases "intellectual property is the most sacred of properties" and "copyright violates creative freedom of expression and access to culture" (to cite the most pragmatic examples of conservative and libertarianist tendencies) differs in that the latter is used currently for its performatic-mantric applications while the former has been repeated over several generations. Conversely, if a name that does not match a right is assigned, and if nomenclature does not allow for its modification, it is important to consider what a certain name effectively means, as names often do not define what they should, and hermeneutics acts refreshingly, to some extent, as a remedy.

If the term copyright is used, the author of such right must be known. If, on the other hand, the term intellectual property is used, one must understand the extent to which real semantic content is used in this designation. This calls for a post-linguistic turn in philosophical hermeneutics. Therefore, names must be given and designated based on their naming without making use of classical metaphysics schemes of the subject-object relationship. Property signifies (tautologically) property, but what is meant by the term "property" should be understood and interpreted following a post-linguistic turn. As for expressions that define copyright genres, there are many other approaches to naming institutes for this legal category available such as related rights, public domains, and so many other typical legal expressions under consideration are clearly deviated from their semantic content to the point to cause the breaking of the semantics elasticity. There is no semantic elasticity that willingly accepts that a right related to copyright may be attributed to a broadcasting company, for instance. On the other hand, once a consecration of this right has occurred, one must understand its limits in regards to its semantic-representative assessment based on reality. One must attempt to understand whether it supports the name assigned to it. This is the purpose of copyright: concepts do not support names assigned to them without prejudice in the system, thus suffering consequences when, for example, large corporations or collective management organisations claim to protect authors (subject-creators) when these subjects are not subject-creators and when their discourse is contaminated by this philosophical argument, resulting in a philosophical deficit of copyright.

Now, these declarations are assigned based on the philosophy of consciousness before the linguistic turn (temporally preceding it, as in the case of Le Chapelier) or simply ignoring the metaphysical overcoming of the contemporary world (as in the case of performatic- mantric allegations that copyright violates creative freedom of expression and access to culture). 
Describing and using each of these mantras is akin to a transmitter implicitly admitting that he or she does not acknowledge an invasion of Law via the philosophy of language while still acting based on a philosophy of consciousness surpassed by the linguistic turn.

Now, with Heidegger and Gadamer, among others, it is no longer possible to argue that the relationship takes place during object naming without considering the positions occupied by the subjects. In other words, following the Copernican Revolution promoted by Kant and following the invasion of Law by the philosophy of language, it must be understood that the use of "performatic mantras" are nothing more than a rhetorical exercise that artificially suits circumstances of copyright to make it appear as if entities of collective management and large corporations do not represent the subject-creator. However, "mantrafication" affects those who seek to increase their profits through uses of content (an expression that in itself exhibits a high degree of semantic inadequacy) in defence of freedoms (of access to culture, creation, expression, etc.).

In this sense, it important to note Heidegger's comments on metaphysics and works of art:

...the metaphysical overcoming is not a rejection, but rather a movement away from a first conceptualisation without a desire for renewal, thus remaining historiographically unreal and historically impossible [...]. That which governs in relation to metaphysics is also applied to meditation on the origins of work of art [...]. ${ }^{18}$

Heidegger thus argues that through copyright, an invasion of the philosophy of language should be permitted (or demanded).

"Performatic mantras" illustrate that the philosophy of consciousness still operates with respect to copyright and that the inherent philosophical deficit of copyright depends on a re-conceptualisation of its historicity, and, to this end, villainies, polarisations, and performaticmantrifications should be discarded.

Intellectual property is not the most sacred of properties, and copyright is not the (grand, unique and in all circumstances) antagonistic of freedoms of expression or artistic creation, the natural predator of freedoms.

Things should be named. If a philosophical centre for contemporary jurists in Brazil (and in many countries) is needed, as Streck notes in his teachings, ${ }^{19}$ copyrightists must understand that the old subject-object scheme has been surpassed and that language is not what one wishes to impose upon it. Language is not a tool much less a cast for what one wants. Language cannot be treated in such an elastic manner as to make it usable in aunscathed way and with impunity.

With respect to copyright, the historical bill has already arrived for the excessively conservative with the overturning of new models such as the Creative Commons and others, and the copyright crisis is overrun by libertarianists. For these, the radical libertarianists, this bill will arrive even sooner if they fail to understand that one cannot say anything about anything. With the post-linguistic turn, mantric declarations of Le Chapelier grow void of meaning, and consorts did not receive philosophical nourishment.

At the very least, moderation must be employed to support dialogue between ideologies in the domain of copyright. However, "performatic mantras" mute the dialogue.

Dialectic positions vary according to the degree of conservatism or libertarianism applied. An example of a more obvious traditional conflict would be that always potentially existing between (I repeat) large Internet providers (companies such as Facebook, Youtube, Google, and Yahoo), whose

\footnotetext{
${ }^{18} \mathrm{M}$ Heidegger, Aportes a la FilosofiaAcerca del Evento [Contributions to Philosophy (of the Event)] (BibliotecaInternacional Martin Heidegger/Editorial Amagesto/Editorial Biblos, Buenos Aires 2003), 397.

${ }^{19}$ Streck, since publishing his work JurisdiçãoConstitucional e Hermenêutica[Constitutional Jurisdiction and Hermeneutics], has arduously promoted the need for laws informed by philosophy and for Brazilian scholars to recognize that the philosophy of language serves as a new paradigm in established relationships of Law that can no longer be understood based on previous philosophical principles of the philosophy of consciousness. See, among other works: L Streck, JurisdiçãoConstitucional e Hermenêutica: Uma Nova Crítica do Direito[Constitutional Jurisdiction and Hermeneutics: A New Critique of Law] ( $2^{\text {nd }}$ ednForense, Rio de Janeiro 2004).
} 
technological tools lack the so-called content, and large rights-holding or rights-representing corporations such as Disney, Apple, Warner Brothers, Sony, Microsoft, and MPAA.

Note that such conflicts are those that are evident at present, as the "techno-communicational society" ${ }^{20}$ brought copyright discussions to technological environments, which in fact, has been historically the case, as only through the proliferation of books (via Gutenberg's press) has copyright become a formally extant field of knowledge.

Thus, in a general sense, the philosophical deficit of copyright stems from (among other factors) semantic deviations from the concept of (intellectual) property that emerged with the first formal laws that have been maintained to this day. Part of this deficit is reflected in the absence of legitimacy in the (complex) relationships that operate in the environments where copyright-protected works are found, which include as participants, the rights-holders, users, and propagators of "performatic mantra" content, which ultimately harms copyright.

Identifying "performatic mantra" meanings leads to the comprehension and to the solution of some aspects of the copyright crisis. It is for the copyrightists of the contemporary times to fend off villainy and biases and build a new copyright. In doing so, an understanding of the value of language and of applications of contemporary hermeneutics to copyright is fundamental.

\footnotetext{
${ }^{20}$ I use the term "techno-communicational society" instead of the traditional term "information society". From the first decade of the 2000s, I have argued that this expression best describes contemporary society since the emergence of technological mechanisms that have introduced more dynamic means of communicating. I realize that this trend has not increased the volume of knowledge generated (with the exception of knowledge about technologies in question), but has increased communication flows. Other discussions have focused on spam emails, work-related e-mails, cookies, hyperlinks, metadata (metatags), etc. Today, more than ten years after I first used this more specific expression, I promote the use of the term techno-communicational society, as countless new ways of communicating have resulted in patterns communicational shock and advance, in regards to technical equipment (e.g., smartphones, tablets) and their numerous applications and in regards to the rise of social networks (e.g., Facebook, LinkedIn), to cite only a few examples.
} 